\title{
Investigación
}

\section{El derecho tributario, ¿derecho administrativo o derecho económico?}

\section{Tax law, administrative law or economic law?}

\author{
Carlos F. Forero Hernández
}

- Recepción: 10/05/2019 • Aprobación: 31/10/2019 • Publicación: 17/12/201

Para citar este artículo

Forero Hernández, C. F. (2019). El derecho tributario, ¿derecho administrativo o derecho económico? Dos mil tres mil, 21.

https://doi.org/10.35707/dostresmil/2101
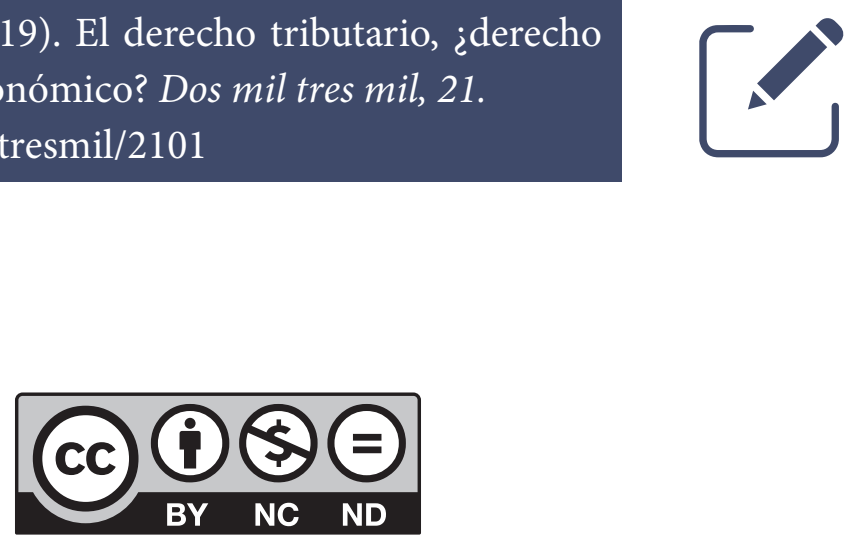

* Grupo de investigación Zoon Politikon, integrante del GedPE, Universidad de Ibagué, ORCID: 0000-0002-9108-2413, carlos.hernandez@unibague.edu.co 
A mi gran maestro, Dr. Hernando A. Hernández Quintero.

Resumen. El objeto de este escrito es diferenciar a la comunidad académica sobre la conveniencia de hablar de derecho económico y no de derecho administrativo cuando se hace referencia al derecho tributario; entendiendo por derecho económico como el derecho de la intervención del Estado en la economía. Este tema tiene un enfoque interdisciplinar que vincula el derecho y la economía.

Abstract. The purpose of this article is to illustrate the academic community the convenience of discussing about economic law, and not administrative law, when referring to tax law. Understanding economic law as the right of the State intervention in the economy. This issue has an interdisciplinary approach that links law and economics.

\section{Palabras claves}

Derecho tributario, derecho administrativo, derecho económico.

\section{Key words}

Tax law, administrative law, economic law. 


\section{Introducción}

Del derecho tributario es muy común afirmar, por ser parte del objeto de estudio de la hacienda pública (Plazas, 2008) o de las finanzas públicas (Miranda, 1999), que su régimen jurídico es de derecho administrativo (Olano, 2007). Otros afirman que, dentro de la clasificación general del derecho, el derecho tributario forma parte del derecho público (Ramírez, 1990). No obstante, se considera que el derecho tributario, por la evidente conexión con la política económica, es de derecho económico; entendiendo por este último como el derecho de la intervención del Estado en la economía (Ariño, 2003).

De esta manera, las líneas que siguen pretenden abordar la conveniencia de hablar de derecho económico y no de derecho administrativo cuando se hace referencia al derecho tributario; de ahí que el tipo de investigación utilizado en este ensayo es demostrativo. Para llevar a cabo este tema es necesario abordarlo de la siguiente manera: 1) Derecho administrativo y derecho económico. Ubicación del tema. 2) Del derecho tributario. Aspectos generales. 3) ¿Es de derecho administrativo el derecho tributario?

\section{Derecho administrativo y derecho económico. Ubicación del tema}

\subsection{Noción doctrinal de la institución: derecho administrativo}

De la institución derecho administrativo se encuentra un sinnúmero de nociones elaboradas por los estudiosos del derecho público. La tarea de elaborar una noción exacta del derecho administrativo ha sido uno de los más complejos problemas de la doctrina (Santofimio, 1996). Dicha complejidad no se presenta exclusivamente frente a la institución derecho administrativo, sino también al acto administrativo que para algunos es la piedra angular de esta rama del derecho público (Sánchez, 1995).

Sea lo primero señalar que algunos juristas han asimilado el derecho administrativo con la ciencia del derecho administrativo; pero se comparte lo explicado por Montaña Plata (2010), al señalar que son dos nociones diferentes, la primera es un cuerpo homogéneo de normas, en tanto que la segunda es aquella construcción de pautas teóricas, principios y bases de ese cuerpo normativo por parte de la doctrina. Esta precisión es bastante importante, dado que evita confusiones cuando se habla de derecho administrativo o ciencia del derecho administrativo.

Un buen sector de la doctrina ha explicado que el derecho administrativo es el derecho de la Administración pública (Ayala, 2009) o de las administraciones públicas (Santamaría, 2011), y otros, como el derecho de la función administrativa (Montaña, 2010). Reconocidos juristas definen el derecho administrativo como una rama del derecho público que estudia lo relacionado con la Administración pública; Younes Moreno (2016), por ejemplo, lo define como "la rama del derecho público concerniente a la Administración"(p. 3). En ese mismo sentido lo entiende el tratadista francés Jean Rivero (2006).

Amado Abril (2017) lo define como una ciencia jurídica que se encarga de estudiar la institución Administración pública, principalmente en sus tres componentes: 1) la función 
administrativa, que alude a la organización y actuación (estructura y actividad), 2) la función pública, que hace referencia a las personas al servicio del Estado, del recurso humano y 3) la gestión pública, que se encarga de estudiar los instrumentos técnicos y económicos como la planeación, control, evaluación y rendición de cuentas.

La anterior noción resulta coherente, pero bastante amplia. Incluye entonces para su estudio además de la función administrativa, la función y gestión pública. En la actualidad no es viable asimilar la función administrativa con la función pública, ni con la gestión pública. Es posible encontrar muchas nociones acerca de esta institución, y todas relacionadas para su estudio con la Administración pública.

De las consideraciones precedentes se ha identificado que el derecho administrativo está muy relacionado con la Administración pública, es tanto que esta ha sido considerada como el principal objeto de estudio de esta rama del derecho público (Rodríguez, 2000). De acuerdo con Omar Guerrero (1997), se entiende por Administración pública como "la actividad del Estado" (p. 24), esto es, referida a la función administrativa (criterio material) (Ayala, 1994).

Por su parte, Ayala Caldas (2009) ha explicado que para definir la Administración pública se puede acudir a dos criterios, por saber: el material y el orgánico. El primero hace referencia a la función administrativa, mientras que el segundo hace referencia a la pluralidad de personas, entidades u organismos ( $\mathrm{u}$ órganos, para algunos) estatales que cumplen la función administrativa. En el mismo sentido explica Rodríguez en su reconocida obra Derecho administrativo general y colombiano (2000).

La Administración pública involucra todas las funciones administrativas que ejercen los distintos órganos del Estado, sin importar a cuál rama del poder público pertenezca, incluyendo las funciones administrativas ejercidas por particulares y autorizadas por la ley; funciones en las cuales se deben aplicar principios consagrados en el artículo 209 de la Constitución Política como son: "Igualdad, moralidad, eficacia, economía, celeridad, imparcialidad y publicidad", dichos principios son explicados, no a profundidad, en la Ley 1437 de 2011 (Código de Procedimiento Administrativo y de lo Contencioso Administrativo). En esta se afirman "funciones administrativas ejercidas por particulares", porque la Constitución, en su artículo 210, ha señalado que "los particulares pueden cumplir funciones administrativas en las condiciones que señale la Ley".

Dichas funciones administrativas se relacionan con la actividad administrativa (Montaña, 2010), la cual conduce a la actuación administrativa (Ayala, 1994), y la que se manifiesta tanto a través de actos administrativos, operaciones administrativas, así como también contratos (Rodríguez, 2000), actuaciones que, sin duda, están sometidas a la teoría del control judicial (Vidal, 2004). Estas manifestaciones deben estar sometidas siempre al cumplimiento del interés general (artículo 209, Constitución Política, 1991), de ahí que el estudio del derecho administrativo debe relacionar dicho cumplimiento. Al respecto, Santofimio Gamboa (1996) ha señalado lo siguiente: "El concepto de derecho administrativo debe comprender, como parte de 
su descripción, el cumplimiento de los cometidos propios del Estado social y democrático de derecho, el interés general y el bien común" (p. 169).

Es bueno señalar que la Administración pública no se manifiesta por sí sola, está muy relacionada con otras disciplinas del conocimiento como la politología, la sociología, la economía, disciplinas que, de acuerdo con Montaña (2010), son aplicadas o desarrolladas por la ciencia administrativa o de la administración. Sobre esta explicación se cree que no hay discusión y la experiencia, o la historia, lo ha demostrado.

\subsubsection{Fenómenos que dan lugar a la transformación del derecho administrativo en derecho económico}

Una vez abordado sobre la institución derecho administrativo, se dará paso a los factores que dan lugar a su transformación en derecho económico, un nuevo paradigma dentro de las ciencias sociales (Pinzón, 2010). Corresponde advertir que dicha transformación no implica el desaparecimiento de la teoría del control judicial, pues, toda actuación (o actividad) administrativa no está exenta de dicho control (Tafur, 1996).

Se han identificado dos fenómenos considerados primordiales en la transformación del derecho administrativo en derecho económico: 1) la ruptura de la ecuación derecho administrativo-Administración pública y 2) la huida (o migración) del derecho público hacia el derecho privado (puede haber otros fenómenos).

De acuerdo con el primero, el tratadista argentino Juan Carlos Cassagne (1999) ha sostenido que la ruptura entre uno y otro se da por "la injerencia progresiva del derecho administrativo contemporáneo sobre esferas de actuación reservadas anteriormente con exclusividad al derecho privado" (p. 107). Dicha escisión se evidencia en la participación de particulares que cumplen funciones administrativas y, también, por la notoria participación de empresas de derecho privado para la prestación de servicios públicos. Importante decir que al evidenciar que las empresas particulares prestan servicios públicos o realizan funciones administrativas (funciones pertenecientes del derecho administrativo), no significa, como es obvio, que perderán su naturaleza de empresa privada; ellas siguen siendo empresas de derecho privado (Forero, 2017a).

Es bueno señalar que un buen sector de la doctrina no reconoce que el derecho administrativo nace y se alimenta de los contenidos del derecho privado, de importantes instituciones de derecho civil, sino a partir de la teoría del servicio público, de la prevalencia del interés general (criterio teleológico). Santofimio (2017), al respecto, ha concluido que "el derecho civil, por siglos, ha constituido el derecho común de la ciencia jurídica e incluso vanguardia importante de la teoría general del derecho" (p. 179), dentro de dicha teoría se encuentra, sin duda, el derecho administrativo.

En la actualidad, en la práctica se identifica que en la Administración pública sus actividades están aplicando con mayor rigor normas de derecho privado (principalmente normas de derecho comercial y civil). Como es el caso, por ejemplo, del régimen jurídico contractual 
de las empresas industriales y comerciales del Estado, el cual forma parte del campo de estudio del derecho público, que aplica con mayor rigor normas de derecho privado (civil y comercial) en sus contratos.

De acuerdo al segundo fenómeno, es decir, de la migración del derecho público hacia al derecho privado, Molina Betancur (2007) ha explicado que hay normatividades en las cuales se señala que, para determinados escenarios relacionados con la Administración pública, no es posible aplicar de manera exclusiva normas de derecho público, también se deben observar con mayor rigor normas de derecho privado (primordialmente normas de derecho comercial y de derecho civil), como es el caso, por ejemplo: el régimen jurídico de la contratación estatal, que está fuertemente impregnada por el derecho privado.

Tratándose de contratos estatales, como aquellos negocios jurídicos celebrados por el Estado, este último se convierte en competidor igual que los particulares y se comporta como ellos. Lo anterior constituye otro ejemplo del paso del derecho público hacia al derecho privado, debido a su participación significativa en las relaciones jurídicas privadas (Forero, 2017a).

Es bueno anotar que dicha huida no conduce necesariamente hacia el derecho privado, sino a la aplicación de regímenes especiales frente al ordenamiento general establecido, aunque dentro del ámbito del derecho público; se caracteriza en la asistencia en los últimos años a una aplicación de principios de derecho privado a las actividades y organización administrativa del Estado (Tafur, 1996).

El abogado Barón Barrera (2016), al realizar un profundo estudio sobre la huida del derecho administrativo hacia al derecho privado, desde el neoliberalismo como en el intervencionismo, concluyó que dicha evasión está ligada al modelo de desarrollo, pues en el neoliberalismo el derecho administrativo huye al derecho privado, pero, sin abandonar el primero sino que se aplica con mayor rigor el segundo, en tanto que en el intervencionismo por parte del Estado, se aplica con mayor rigor el derecho administrativo, pero, sin abandonar el derecho privado. Esto lo resume Barón (2016): “Tanto en neoliberalismo como en el intervencionismo de Estado se aplica el derecho público y privado, cuya sumatoria es el derecho económico” (p. 33).

Las anotaciones precedentes permiten afirmar que el derecho económico surge a partir de la influencia recíproca entre normas de derecho público y normas de derecho privado. Por eso Barón (2016) define el derecho económico como el derecho mixto con relación al derecho público y al derecho privado. Enseguida se abordará la noción doctrinal y el carácter autónomo de la institución derecho económico, así como una de las metodologías utilizadas en el campo de estudio del derecho económico, el Análisis Económico del Derecho, AED.

\subsection{Definición doctrinal de la institución: Derecho económico}

Sea lo primero señalar que la relación derecho y economía ha sido un tema de discusión en la doctrina, igual sucede con el tema de la existencia del derecho económico. En la actualidad la doctrina mayoritaria reconoce la existencia de la estrecha relación entre el derecho y la 
economía, tanto así que se habla de un derecho económico que se encarga de estudiar en conjunto estas dos áreas de conocimiento.

Se podría decir que el derecho económico surge a partir del estudio en conjunto entre el derecho y la economía. Algunos, entre ellos Romero Alvarado (2013), han sostenido que la relación existente entre estas dos áreas de conocimiento es sinónimo del Análisis Económico del Derecho (AED) (más adelante se abordará la noción del AED). El estudio en conjunto de estas áreas de conocimiento contribuye al objetivo de ampliar el espectro argumentativo de juristas y economistas (Franco, 2013).

Del derecho económico, igual como sucede con la institución derecho administrativo, se han dado tantas nociones como autores sobre el tema. Algunos han definido el derecho económico como el derecho de la intervención del Estado en la economía (Ariño, 2003) y, otros, como el derecho mixto con relación al derecho público y al derecho privado (Barón, 2016). Velilla Moreno (2013) lo entiende como "el derecho del desarrollo económico" (p. 87). Para efectos de este trabajo se acogerá la primera definición.

Farina (1999) da una definición más precisa:

El conjunto de normas que rigen la organización de la economía por los poderes públicos y regulan las actividades económicas de las personas privadas y del Estado, a fin de dar cumplimiento a la política económica puesta en práctica por el Estado. (p. 46).

La definición proporcionada por Farina tiene estrecha relación con la institución intervención del Estado en la economía, la cual forma parte del campo de estudio de la política económica; es uno de los temas transcendentales de la Constitución económica (Sánchez, 2007). Entendiendo por intervención del Estado en la economía, según Hernández Quintero (1991), como "el conjunto de normas con las cuales se pretende regular y delimitar la autonomía de los particulares a fin de garantizar el logro de los intereses de la comunidad, esto es, el bien común" (p. 21).

La intervención en la economía por parte del Estado se traduce en acciones de las autoridades administrativas tendientes a regular las actividades económicas; esta debe estar, siempre, acompañada de una supervisión permanente del mercado. En la labor de dirección e intervención atribuye al Estado la función esencial de garantizar que la economía funcione adecuadamente. Dicha intervención forma parte del campo de estudio del derecho económico, más que del derecho administrativo (Vidal, 2004).

Ortega Cárdenas (2014) ha explicado que la intervención del Estado en la economía se justifica para alcanzar la equidad en la distribución y la riqueza nacional, cuando los mercados no pueden por sí solos alcanzar sus objetivos. Recuérdese que la economía es incapaz de darse sus propias reglas, esta necesita unas reglas que la protejan y en ellas se encuentran las herramientas de dirección, de intervención y de regulación. 
Por eso tienen razón Carrillo \& Pinzón (1985), al señalar que la economía requiere de reglas jurídicas que aseguren la adecuada utilización de los factores de producción, distribución y consumo de bienes y servicios: "El funcionamiento armonioso de un sistema económico determinado requiere un cierto número de reglas de derecho que aseguren la apropiación y el uso de los factores de la producción, de los productos y de los servicios"(p. 64).

Por su parte, Sánchez Agesta (1977), citado por Carrillo \& Pinzón (1985), ha señalado que la intervención del Estado en la economía se puede presentar en dos planos. Uno, definiendo en el orden constitucional los principios que constituyen los supuestos de un sistema económico. Dos, estableciendo instituciones administrativas o regulaciones en el plano legislativo o reglamentario con el fin de dirigir el proceso económico o promover las reformas o desarrollos del orden económico o social. De ahí surge la importancia de estudiar los distintos tipos de intervención de poder estatal en los procesos económicos identificados por la Corte Constitucional en Sentencia C-150 de 2003:

Ahora bien, la intervención del Estado en la economía puede ser de diferente tipo, sin que siempre pueda efectuarse una diferenciación clara entre las formas de intervención correspondientes. Así, por ejemplo, en la doctrina se habla de intervención estatal global, cuando versa sobre la economía como un todo, sectorial, cuando recae en una determinada área de actividad, o particular, si apunta a una cierta situación como por ejemplo a la de una empresa; de intervención estatal directa, cuando recae sobre la existencia o la actividad de los agentes económicos, o indirecta, cuando está orientada no a la actividad económica propiamente dicha sino al resultado de la misma; intervención unilateral, cuando el Estado pacta con los agentes económicos las políticas o programas que propenden por el interés general; intervención por vía directiva, cuando el Estado adopta medidas que orientan a los agentes económicos privados, o intervención por vía de gestión, cuando el Estado se hace cargo el mismo de actividades económicas por medio de personas jurídicas generalmente públicas. (Sentencia C-150, 2003, p. 91).

En relación con lo anterior, Barón (2016) define las herramientas que le sirven para intervenir en la economía: a) la política económica y b) la planeación económica. La primera hace alusión a las decisiones económicas para hacerle frente a la inflación y al desempleo; y la segunda se refiere a la forma deliberada que el Estado tiene para influir en las actividades económicas, de una manera eficiente y obviamente con el mínimo de costo social. En la actualidad, la doctrina ha resaltado la importancia de la planeación económica en la intervención del Estado en la economía; Myrdal (1982), citado por Carrillo \& Pinzón (1985), al respecto, ha señalado lo siguiente:

La intervención estatal es la que provoca el nacimiento de la planeación, porque como las intervenciones estatales fueron aumentando cada vez en más sectores, hubo que hacer intentos para coordinarlas racionalmente, así que la planeación resultaba la alternativa mejor en medio del caos resultante de las múltiples intervenciones estatales sin coordinación y promotoras del desorden. (Carrillo \& Pinzón, 1985, p. 61). 
De esta manera, el derecho económico se caracteriza como el derecho del dirigismo económico del Estado con la utilización de dos importantes herramientas económicas: la política económica y la planeación económica. Es bueno mencionar que hay algunos economistas, entre ellos Adam Smith, citado por Romero (2013), que no comparten la aplicación de medidas políticas que supongan control y regulación estatal en la economía (en otras palabras, la aplicación de intervención del Estado en la economía), dado que la economía o el mercado "se regula de forma natural por las leyes de la oferta y la demanda" (p. 275). La práctica, o si se quiere la historia, ha demostrado que la economía es incapaz de manifestarse por sí sola, por el contrario, necesita de determinadas reglas, de ahí la aplicación de intervención del Estado en la economía.

En las consideraciones precedentes se encuentra una evidente diferencia entre derecho administrativo y derecho económico. El primero comprende la regulación de la función administrativa de los órganos o autoridades del Estado, incluyendo aquellas funciones administrativas ejercidas por particulares autorizados por la Ley. En tanto que el derecho económico comprende el estudio de la intervención del Estado en la economía con el empleo de dos herramientas económicas: la política económica y la planeación económica.

\subsection{1. ¿Es autónomo el derecho económico?}

La autonomía del derecho económico ha sido objeto de discusiones en la doctrina; algunos aceptan su carácter autónomo, otros no. Se comparte el criterio de Barón (2016), quien acepta el carácter autónomo; este autor señala que el derecho económico efectúa "una influencia recíproca entre derecho público y privado, convirtiéndose de esta manera en una rama autónoma del derecho, autónoma porque al aplicar las dos ramas del derecho corrige las inexactitudes que se presentan al aplicar una rama por separado" (p. 42).

Teniendo en cuenta al mismo autor (Barón, 2016), si se mira, por ejemplo, el derecho de los servicios públicos domiciliarios, en materia contractual su régimen jurídico es prevalentemente de derecho privado (normas comerciales y civiles), pero no excluye la aplicación de normas y principios de derecho público (Atehortúa, 2017), una aplicación híbrida de normas, tanto de derecho privado como de derecho público, que confiere al derecho económico su autonomía y, "de esa manera se vale de dicho carácter para hacer uso de la pluralidad de principios que determinan su propia naturaleza económica" (Forero, 2017b, p. 147).

\subsubsection{Análisis económico del derecho (AED): una metodología de evaluación de las instituciones jurídicas con criterios económicos}

Una de las metodologías más utilizada por juristas y economistas en el campo de estudio del derecho económico corresponde el Análisis Económico del Derecho (AED), conocida también como Law and Economics (en español derecho y economía). El representante más influyente de esta metodología es precisamente Richard Posner, de la escuela neoinstitucionalista (Romero, 2013). 
Se entiende por AED como aquella metodología de evaluación de las instituciones jurídicas con criterios económicos (Forero, 2017a), o como lo explica Ramírez Grisales (2013) "como la aplicación de la ciencia económica para estudiar algunos aspectos relacionados con el derecho" (p. 71). Algunos asimilan a esta metodología con el estudio de la relación entre el derecho y la economía. Franco Vargas (2013) ha resaltado la importancia de estudiar y aplicar el AED por ser una herramienta que "suministra argumentos para demostrar la coherencia interna del derecho y de esa manera reducir la vaguedad y ambigüedad de conceptos indeterminados dentro del mismo derecho" (p. 7).

De acuerdo con Amador Cabra (2014) el AED está orientado a que: a) la interpretación y evaluación de las normas se realiza desde una óptica económica; b) la racionalidad con que se dota a las leyes y al sistema normativo es la misma racionalidad que utiliza la teoría microeconómica en su construcción teórica; y c) el entorno legal produzca incentivos para que los agentes se comporten eficientemente. Importante es mencionar, y con acierto lo explica Richard Posner, citado por Amador (2014), que el AED no pretende reemplazar la lógica jurídica, sino complementarla mediante el uso de la economía en relación con una gran cantidad de fenómenos jurídicos.

Uno de los aportes que han hecho los juristas y economistas con el empleo del AED es el estudio de la eficiencia (Amador, 2014). Este es aplicable en todos los escenarios, es decir, en el derecho público y en el derecho privado. La eficiencia, para efectos de este escrito, hace referencia a que los agentes económicos optimicen el uso del tiempo y de los demás recursos. Esta institución ha sido estudiada con la noción de economía que igualmente ha sido estudiada con la noción de ahorro, de ahí la denominación: eficiencia económica.

Amador Cabra (2014) explica que la eficiencia para el AED es relevante porque permite establecer cuáles son las condiciones para que los consumidores y productores optimicen en el mercado: "La categoría eficiencia económica se refiere al mejor uso alternativo que los agentes económicos hacen de los factores productivos” (p. 27). Franco (2013) señala que la eficiencia económica está relacionada con la eficiencia en término de Pareto, esto es, "una asignación de recursos es eficiente si no es posible mejorar a uno o a varios individuos sin necesariamente empeorar a otro u otros" (p. 32).

Abordadas las nociones de derecho administrativo y de derecho económico, así como los factores que dan lugar a la transformación del derecho administrativo en derecho económico, enseguida se relacionará la noción y los principios constitucionales del derecho tributario.

\section{Del derecho tributario. Aspectos generales}

\subsection{Noción doctrinal de la institución: derecho tributario}

Sea lo primero señalar, de acuerdo con Barros Carvalho desde su reconocida obra Teoría de la norma tributaria (2016), que la tarea de elaborar una noción exacta del derecho tributario no es sencilla. También se ha discutido en la doctrina sobre si el derecho tributario es un derecho 
autónomo o no (Avellaneda, 1997), es uno de los sucesivos debates y muchos de ellos acalorados, pero siempre interesantes.

Según Olano García (2007), el derecho tributario es "aquella parte del derecho administrativo que expone los principios y las normas relativas a la imposición y a la recaudación de los tributos y analiza las consiguientes relaciones entre el Estado y los particulares en materia tributaria" (p. 143). De esta manera, el derecho tributario es de derecho administrativo.

El derecho tributario está conformado por un conjunto de leyes que son fuente de la obligación tributaria. Dichas leyes definen los sujetos (activo y pasivo), el hecho gravable, la base gravable y la tarifa. Los procedimientos administrativos que establecen en las leyes que hacen posible la aplicación de las normas generales de obligaciones tributarias, a nuestro criterio, son de derecho administrativo, más que de derecho tributario, porque hacen referencia a procedimientos que permiten realizar el recaudo, control, investigación, liquidación, discusión, cobro, etc.

El derecho tributario estudia la pretensión crediticia tributaria (Bravo, 2012), específicamente los tributos (Barón, 2016). Por eso Plazas Vega, en su reconocido artículo Relación entre el derecho de la hacienda pública y el derecho tributario (2008), ha definido el derecho tributario como "el conjunto de normas jurídicas que regulan los tributos" (p. 121). Esta rama del derecho tiene por objeto el estudio de los tributos.

El tributo es un recurso que el Estado obtiene por medio de la coerción, que nace de su poder de imperio y tiene su expresión a través de la Ley (Insignares \& Sánchez, 2010). Este se caracteriza como una fuente de los ingresos públicos, pues, tal como lo explica Ortega (2014), las fuentes de los ingresos públicos son: los impuestos, tasas y contribuciones, que son la tripartita clasificación del tributo (Avellaneda, 1997); por eso Barón (2016) define el derecho tributario como el derecho de los ingresos públicos.

En relación con el impuesto, como una de las fuentes de los ingresos públicos, este cumple un importante papel en el gasto público, pues su justificación económica es financiar parte del gasto público que no fuere financiable con otros recursos, tales como, entre otros, los de dominio público; es, entonces, un verdadero instrumento financiero (Muñoz, 2010). Si el gobierno desea realizar un mayor gasto público, eso implica también un aumento de recaudo de impuestos (o tributos) precisamente para su cobertura.

Por eso tiene razón Cadavid Arango (2014) al señalar que: "En cumplimiento de sus fines, el Estado realiza gastos, por lo que debe procurar recursos económicos para cubrirlos. Los ingresos del Estado provienen entre otras fuentes, de los tributos" (p. 222). Con el impuesto el Estado recauda los medios para cumplir adecuadamente sus propósitos.

Ramírez Cardona (1990) también ha señalado que para atender los gastos del Estado la estrategia más utilizada son los impuestos directos a los ciudadanos por la propiedad y la renta (impuesto de renta, por ejemplo), y los indirectos provenientes del consumo y la importación o exportación de bienes (Impuesto al Valor Agregado, IVA, por ejemplo). En relación con lo 
anterior se comparten las reflexiones ofrecidas por Bravo Arteaga (2009) al señalar que el gasto público implica efectos positivos en la economía de un país:

En el momento de la realización del gasto o de la inversión por parte del Estado, se produce un efecto expansivo en la economía, por regla general, especialmente si los recursos se colocan en los sectores más pobres de la población, que tienen una elevada propensión al consumo. (Bravo, 2009, p. 71).

Se tiene, entonces, que el fin fundamental del impuesto está en la recaudación de los recursos necesarios para realizar los gastos e inversiones públicas, para "el cumplimiento de la política fiscal del Estado y el mejoramiento social y económico del pueblo” (Barón, 2016, p. 85). No se debe perder de vista que el impuesto no solamente tiene una finalidad puramente fiscal, sino también económica.

Se puede afirmar que el gasto público y el impuesto (o el tributo) son instituciones más importantes en el campo de estudio de la política tributaria (instrumento económico que utiliza el Estado para el estudio de recaudo de tributos), así como también de la política fiscal como aquel instrumento económico que permite estimular o desestimular la economía (o sectores económicos) a través de la imposición y recaudo de impuestos; ambas políticas son dependientes de la política económica y, por tanto, forman parte del derecho económico y no del derecho administrativo el cual estudia la función administrativa.

Por su parte, respecto de las relaciones jurídicas tributarias, es decir, relaciones entre los sujetos activos y pasivos frente a determinados tributos, se considera que estas no hacen parte del derecho administrativo, son propias del derecho tributario; por eso, un buen sector de la doctrina ha definido el derecho tributario como el derecho de las relaciones jurídicas tributarias. De esta manera, el derecho tributario estudia las relaciones jurídicas tributarias (Estado y contribuyentes) y no las relaciones jurídicas entre el Estado y los particulares, menos a la función administrativa, estas últimas son propias del derecho administrativo.

Si se relaciona el derecho administrativo con el derecho tributario en lo que tiene que ver con la obtención efectiva del tributo, pues, se requieren de ciertas autoridades administrativas para realizar los cobros o recaudos de tributos, control, investigaciones, etc. (Briceño, 2012); también se relaciona con el derecho administrativo, la imposición de sanciones frente al incumplimiento de normas tributarias, escenario que se conoce como el derecho administrativo sancionador (Forero, 2016).

\subsubsection{Fundamento constitucional del sistema tributario y sus principios}

Los estudiosos del derecho tributario han sostenido que en el campo de estudio del régimen tributario (o del sistema tributario, para algunos) se ha fundamentado en una serie de principios que hacen coherentes las relaciones entre contribuyentes y Estado. No se puede perder de vista del debate en la doctrina que ha surgido sobre si los principios son criterios auxiliares de la actividad judicial y administrativa o son estudiados como fuentes del derecho. 
El principio más profundizado por la doctrina es el señalado en el numeral 9 del artículo 95 de la Constitución Política, el cual señala el deber del ciudadano a "contribuir al financiamiento de los gastos e inversiones del Estado dentro de conceptos de justicia y equidad”, una clara manifestación del principio de solidaridad (Muñoz, 2010).

El fundamento constitucional del sistema tributario se encuentra en el artículo 363 de la Carta Política al señalar que "el sistema tributario se funda en principios de equidad, eficiencia y progresividad" - continúa la norma - "las leyes tributarias no se aplicarán con retroactividad". De este artículo y otras disposiciones relacionadas con el sistema tributario (o con el derecho tributario) han permitido a la doctrina afirmar la existencia de la constitucionalización del derecho tributario; con la nueva Carta se constitucionalizó el derecho tributario.

En la literatura jurídica es posible encontrar un sinnúmero de principios aplicables al sistema tributario; pero en esta oportunidad se indicarán los mencionados en el citado artículo 363.

El principio de equidad. Cruz de Quiñones, citada por Avellaneda Bautista (1997), explica que este principio opera cuando las cargas tributarias recaen en los contribuyentes en proporción a su capacidad de pago; se da la equidad horizontal cuando los contribuyentes pagan iguales impuestos siendo iguales sus niveles de renta; se da la equidad vertical cuando los contribuyentes pagan distinta cantidad de impuesto, dado a los diferentes niveles de renta.

El principio de eficiencia. Hace referencia a que el recaudo del tributo se realice con los menores costos y con las mayores facilidades para el contribuyente en el correspondiente pago. Ariza Sánchez (2000) explica que este principio está relacionado "con los fines u objetivos que persiguen los tributos y la forma en que se obtienen" (p. 10).

El principio de progresividad. Se asimila a la equidad vertical, es decir, a la capacidad de pago; hace referencia en que a los contribuyentes se les grave con impuestos según su capacidad de pago, pues a mayor capacidad económica corresponde un mayor impuesto.

Este principio no es aplicable a todos los tributos, solo a aquellos donde se tiene en cuenta, para la determinación del tributo, la capacidad económica o contributiva del sujeto pasivo, mayor capacidad económica se imponga una mayor carga impositiva, como es el caso, por ejemplo, el impuesto de renta de personas naturales, el cual la tarifa aumenta dependiendo de los ingresos o renta. Se considera, entonces, que el IVA (Impuesto sobre el Valor Agregado), que es un impuesto indirecto, sigue siendo regresivo pues no se toma en cuenta la capacidad económica o de pago de los contribuyentes, pero su creación o establecimiento se justifica por su fácil recaudo.

El principio de irretroactividad de las normas tributarias. De acuerdo con Avellaneda (1997) este principio consiste en que las normas tributarias no pueden regular hechos tributarios sino a partir de su promulgación, es decir, "no pueden tener vigencia sobre períodos anteriores a la misma Ley” (p. 111). Respecto de los impuestos de período, el artículo 338 de la Carta Política precisó que las leyes, ordenanzas o acuerdos que "regulen contribuciones en las que la base sea el resultado de hechos ocurridos durante un período determinado, no pueden aplicarse sino a 
partir del período que comience después de iniciar la vigencia de la respectiva ley, ordenanza o acuerdo".

Otro principio que forma parte del campo de estudio del poder tributario (como aquella función normativa de crear, modificar o derogar los tributos) (Insignares \& Sánchez, 2010) es el principio de legalidad del tributo y hace referencia que no debe haber un tributo sin representación. La Alta Corporación constitucional ha señalado que el principio de legalidad del tributo tiene las siguientes características:

a) Esexpresión derepresentación popularydel principiodemocrático,b) materializa el principiodepredeterminación del tributo, según el cual una lexpreviay certa debe señalar los elementos dela obligación fiscal, c) brindaseguridadalosciudadanosfrenteasusobligacionesfiscales, d) respondealanecesidadde promover una política fiscal coherente e inspirada en el principio de unidad económica, especialmente cuando existen competencias concurrentes donde confluye la voluntad del Congreso y la de las asambleas departamentales o de los concejos municipales, e) no se predica únicamente de los impuestos, sino que es exigible también frente a cualquier tributo o contribución (en sentido amplio), f) de conformidad con el mandato constitucional contenido en el artículo 338, no solo el legislador, sino también las asambleas y los concejos están facultados para fijar los elementos constitutivos del tributo, g) la ley, las ordenanzas y los acuerdos, sin resignar sus atribuciones constitucionales, pueden autorizar a las autoridades de los distintos niveles territoriales, dentro de los límites señalados en ellas, para fijar las tarifas de las tasas y contribuciones que cobren a los contribuyentes. (Sentencia C-891, 2012).

De esta manera, la Constitución Política establece los principios que orientan el régimen tributario o el sistema tributario (para algunos), y actúa como criterio de interpretación y orienta a la actuación del Estado en materia impositiva. Es de señalar que estos principios no son aplicables exclusivamente a los impuestos o tributos, pues, los beneficios tributarios, las exenciones tributarias, por ejemplo, también deben aplicar dichos principios.

Es la Constitución Política la primera herramienta de protección para los contribuyentes, evitando que el Estado, a través del Legislador (quien goza de la soberanía fiscal), cometa arbitrariedades en detrimento del contribuyente; por eso tiene razón Romero (2013) al señalar lo siguiente:

Así, desde la óptica del derecho, el problema está en ¿cómo establecer los principios doctrinales con objeto de regular las relaciones jurídicas tributarias? Estos nacen de manera que su función sea ejercer control en el marco de actuación tanto del sujeto pasivo como del sujeto activo, y para ello se debe establecer un régimen jurídico específico, dicho régimen es: la Constitución. Para que se cumplan, deben convertirse en derecho positivo constitucional, solo así evita que el Estado cometa abusos, arbitrariedades y discriminación en detrimento del contribuyente, es allí donde nace el principio de proporcionalidad o de justicia que hoy prevalece en nuestra actual Constitución Política. (Romero, 2013, pp. 274-275). 
Es bueno decir que hay conductas que afectan de manera negativa al sistema tributario como es el caso, por ejemplo, la evasión fiscal (o evasión tributaria, para algunos), conducta que reduce o evita el impuesto. La Corte Constitucional en varias ocasiones ha señalado que la evasión se evidencia a partir de la violación de la normatividad que rige el sistema tributario, ya sea por acción u omisión del contribuyente, que da lugar a un menor recaudo de impuestos por parte del fisco (entre otras: Sentencia C-015, 1993).

\subsection{2. ¿Es autónomo el derecho tributario?}

Se ha preguntado con frecuencia en la academia respecto de la autonomía del derecho tributario. Algunos señalan que es un derecho autónomo, otros señalan que no lo es. Muñoz Martínez (2010) afirma que el derecho tributario es autónomo:

El punto que queremos destacar en esta oportunidad es precisamente el del reconocimiento de plena autonomía al derecho tributario como rama jurídica que se ubica en el derecho público, porque el sujeto de las relaciones jurídicas que regula es el Estado, los intereses que tutela son de orden colectivo y los fines a los que atiende son de utilidad general. (Muñoz, 2010, p. 57).

Avellaneda (1997) afirma que el carácter de autónomo se identifica a partir de la especialidad que reviste. Es posible afirmar que el derecho tributario no es un derecho autónomo frente a todo el ordenamiento jurídico; pues, tal como se explicó y a manera de ejemplo, el derecho tributario no puede salirse del marco institucional señalado por la Constitución Política (por el derecho constitucional), donde se encuentran límites en los principios que informan el régimen o sistema tributario (los señalados en el artículo 363, por ejemplo).

En relación con lo anterior, un buen sector de la doctrina ha afirmado que en el derecho tributario se debe aplicar en primer lugar los principios constitucionales (Ariza, 2000), otros han señalado que se debe aplicar en primer lugar los principios elementales de la macroeconomía (Miranda, 1999). Se considera que el derecho tributario, igual como sucede con el derecho económico, se encuentra desarrollado, y en ella convergen o fusionan como en ninguna otra, los principios jurídicos y los económicos.

\section{3. ¿Es de derecho administrativo el derecho tributario?}

Es muy común afirmar que el derecho tributario, por ser parte del objeto de estudio de la hacienda pública o de las finanzas públicas, es de derecho administrativo (Olano, 2007). No obstante, en el presente trabajo se pretende afirmar que es de derecho económico, entendido como el derecho de la intervención del Estado en la economía. 
En esta oportunidad se expone la relación del derecho tributario con la noción de la institución derecho económico como el derecho de la intervención del Estado en la economía, para concluir que no es conveniente hablar de derecho administrativo cuando se hace referencia al derecho tributario, sino propiamente de derecho económico.

3.1. Desde la noción del derecho económico como el derecho de la intervención del Estado en la economía

La institución intervención del Estado en la economía es desarrollada ampliamente por juristas y economistas (Palacios, 1975). Es una institución propia de la denominada Constitución económica (denominación bastante difundida en Alemania) y, por tal razón, hace parte del derecho económico (Vidal, 2004). Dicha institución no se escapa del apoyo del derecho tributario o de la política tributaria (Barón, 2016) y de ahí surge la relación economía y derecho.

Cuando en el mercado se presentan distorsiones surge la necesidad de intervención por parte del Estado para que introduzca las correcciones apropiadas. De las correcciones se encuentra, desde el punto de vista tributario, entre otras y las más comunes, la posibilidad de utilizar los impuestos (Piffano, 2012) como verdaderos instrumentos económicos. Por sus distorsiones, la economía requiere de la intervención por parte del Estado.

Lo anterior es un claro ejemplo de aplicación de la política tributaria, como una de las herramientas económicas que tiene el Estado para intervenir en la economía (Miranda, 1999). La política tributaria es una política de carácter económico que vincula la realidad económica del sector privado con el Estado (Quiroga, 2016). Uno de los principales objetivos de dicha política corresponde a la estabilidad económica del país. En este orden, se considera que el derecho tributario es el derecho de la intervención del Estado en la economía a través de la política tributaria.

De esta manera, el Estado perfectamente puede utilizar los impuestos para corregir distorsiones en el mercado, y según sea la modalidad del impuesto, o incidencia sobre determinado sector de la economía, puede tener alguno o algunos de estos efectos: a) contribuir a atenuar las fluctuaciones económicas; b) contribuir a la redistribución del ingreso nacional; c) desalentar el consumo suntuario y superfluo; d) fomentar el ahorro forzoso o inversión de los empresarios, en lugar de la distribución de utilidades entre los socios (Ortega, 2014).

En relación con lo anterior, se comparte la explicación de Miranda Talero (1999) al señalar que "el sistema moderno impositivo utiliza diferentes posiciones frente a los contribuyentes para intervenir en la economía del país" (p. 151). De ahí que la política tributaria se comporta como una de las verdaderas herramientas económicas que cuenta el Estado para corregir las distorsiones del mercado.

Por su parte, los economistas enseñan que hay dos reglas para ser aplicadas en la intervención en la economía por parte del Estado para efectos de aumentar o reducir la actividad económica, y ambas aplican la política tributaria, por saber: 1) Para aumentar el nivel de actividad económica, incrementar los gastos del gobierno o reducir los impuestos; 2) para reducir el nivel 
de actividad económica, disminuir los gastos del gobierno o aumentar los impuestos (Charles Pool \& M. LaRoe, 1991).

La intervención del Estado en la economía es una tarea prioritaria (o indispensable) en un Estado social de derecho como el nuestro, pues, está orientada, siempre, hacia la consecución del bienestar general. Dicha consecución se obtiene, entre otros, a través del gasto público, de manera preferente el gasto público social. Se comparte por quienes afirman que la intervención estatal en la economía es un instrumento para el cambio social en la búsqueda de un desarrollo de la sociedad (Carrillo \& Pinzón, 1985).

El gasto público también es una forma de intervención en la economía por parte del Estado, es una necesidad estatal (Parra \& Patiño, 2010); de ahí cumple un importante papel el tributo, pues, su fin fundamental está en la recaudación de los recursos necesarios para poder realizar los gastos e inversiones del Estado (Muñoz, 2010). El tributo tiene una finalidad financiera de cobertura del gasto público, en función reguladora de la economía y de la sociedad.

Por eso Miranda (1999) ha señalado que la política tributaria se ha convertido por excelencia en una herramienta económica para que el Estado pueda recaudar fondos destinados a satisfacer las necesidades de sus asociados; la política tributaria debe ser vista como un instrumento para la promoción de inversión (Piza, 2013). Desde luego, el Estado debe invertir adecuadamente los recursos públicos, pues, de ahí se logra satisfacer el interés general.

Como se evidenció, el empleo de las políticas tributarias para las correcciones (o subsanar, si se quiere) de los déficits fiscal también es una forma de intervención del Estado en la economía. En las últimas administraciones se ha identificado la importancia que cobra la utilización de políticas tributarias como respuesta a la necesidad de recursos para subsanar el déficit fiscal, pues, se han ideado diversas estrategias para incrementar los ingresos públicos (incrementar las tarifas de los impuestos) y disminuir los gastos de la misma manera (Parra \& Patiño, 2010).

A su turno, Velilla Moreno (2013), al explicar los principios de origen intervencionista, ha señalado que la expedición de leyes tributarias se comporta como una de las tantas formas de intervención del Estado en la economía y, por tal razón, forma parte del campo de estudio de la denominada Constitución económica, así como también del denominado derecho económico. Es decir, la intervención del Estado en la economía se manifiesta también a través de la expedición de leyes tributarias, eso sí, ajustadas siempre a los principios del sistema tributario y en miras de mejorar la economía (o corregir las distorsiones del mercado).

\subsubsection{Los beneficios tributarios también son formas de intervención del Estado en la economía con} el fin de estimular determinadas actividades económicas

También es una forma de intervención en la economía por parte del Estado con el empleo de la política tributaria, los conocidos beneficios tributarios. Hernández Quintero (2015) ha señalado que la intervención del Estado en la economía puede efectuarse de múltiples formas "bien puede tratarse de estímulos a la iniciativa privada, como la creación del Certificado de 
Reembolso Tributario (CERT) para los exportadores, fomento a través de créditos [...] para los agricultores [...]” (p. 56).

Dichos estímulos deben estar orientados a estimular (o incentivar) determinadas actividades económicas o para incrementar la producción y comercialización determinados bienes. Estos forman parte del campo de estudio de los incentivos que explican los economistas en el AED. Según la RAE un incentivo "es un estímulo que se ofrece a una persona, grupo o sector de la economía, con el fin de elevar la producción y mejorar los rendimientos" (Franco, 2013, p. 118).

La Corte Constitucional también ha señalado que los beneficios tributarios son formas de intervención del Estado en la economía al señalar lo siguiente:

La facultad de dirección e intervención en la economía, que se reconoce al Estado social de derecho con miras a facilitar su función de promotor de la dinámica colectiva hacia la consecución de las condiciones materiales que garanticen la eficacia real de los derechos fundamentales de las personas, de conformidad con lo dispuesto por el artículo 334 de la Constitución se lleva a cabo por mandato de la ley a través de diversos procedimientos, dentro de los cuales se encuentran las actividades de fomento. A través de las actividades de fomento el Estado interviene para dar pleno empleo a los recursos humanos y asegurar que todas las personas, en particular las de menores ingresos, tengan acceso efectivo a los bienes y servicios básicos también para promover la productividad y la competitividad.

Ahora bien, las formas de intervención para fomento de la economía o de un sector de ella, pueden revestir diversas modalidades. Por ejemplo, el legislador puede estimular un sector económico mediante la política tributaria, adoptando exenciones, tasas o tarifas reducidas al sector económico que considera oportuno fomentar. (Sentencia C-1108, 2001, p. 28).

Los beneficios tributarios son aquellos que implican reducción (o eliminación, para algunos) de la carga tributaria con el objetivo de estimular determinadas actividades económicas. La Corte Constitucional en Sentencia C-989 (2004) ha resaltado que el beneficio tributario es todo aquello que disminuya la base gravable o el impuesto a pagar, eso sí, acorde a los principios de justicia, equidad y progresividad:

Si bien existen en la legislación tributaria disposiciones que consagran disminuciones de la carga tributaria, no todas ellas tienen el propósito de estimular, incentivar o preferenciar determinados sujetos o actividades, sino que pretenden no perjudicar o hacer efectivos los principios de justicia, equidad y progresividad. Por lo tanto, para que una determinada disposición se pueda considerar como un beneficio tributario, debe tener esencialmente el propósito de colocar al sujeto o actividad destinataria de la misma, en una situación preferencial o de privilegio, con fines esencialmente extrafiscales. (Sentencia C-989, 2004, p. 20).

De esta manera, dichos beneficios son disposiciones de dirigismo económico y son amparados por la Constitución (artículo 334), cuando están acordes a los principios del sistema tributario que se han mencionado con alguna anterioridad. 
Por su parte, como se evidenció, los beneficios tributarios generan una menor imposición para los contribuyentes (disminuir su carga tributaria), eso sí, en aras de estimular determinadas actividades; implican también un alto gasto fiscal (o alto costo fiscal, para algunos) para el Estado, dado que representan un menor recaudo de los tributos. Plazas (2019) es partidario la eliminación de la totalidad de los incentivos y beneficios tributarios en aras de incrementar el recaudo. Pero, otros consideran que el establecimiento de los beneficios tributarios a actividades privadas se justifica porque coadyuva el desarrollo económico, la redistribución del ingreso y la riqueza.

Estos beneficios se diferencian de las minoraciones estructurales, en razón a que estas últimas no involucran un gasto fiscal para el Estado (Sarmiento, 2013), son de carácter indispensable e imprescindible (Sentencia C-540, 2005). Sobre el concepto y la distinción de las minoraciones estructurales con los beneficios tributarios, la Corte Constitucional ha explicado lo siguiente:

Acogió, entonces, este Tribunal la distinción establecida por la doctrina fiscal entre beneficios tributarios y las así denominadas genéricamente minoraciones estructurales, según la cual estas últimas si bien reducen la carga impositiva o excluyen o exonera a un determinado sujeto del deber de contribuir representan simplemente un reconocimiento de los principios de tributación, y sin ellas el sistema tributario o un determinado impuesto, no podrían ser calificados a primera vista como justos equitativos y progresivos. En otras palabras, aquellas previsiones legales que solamente pretenden reconocer y hacer efectivos los más elementales principios de la tributación no constituyen verdaderos incentivos, sino simplemente maneras o formas de no hacer de un tributo una herramienta de castigo o un elemento de injusticia.

Las minoraciones estructurales, a pesar de suponer un tratamiento diferente de los sujetos gravados, se caracterizan porque no tienen como propósito principal incentivar o crear preferencias sino coadyuvar a la definición y delimitación del tributo y a la aplicación práctica de los principios de tributación. Su finalidad no es incentivar, estimular o preferir determinados sujetos o actividades sino simplemente "no perjudicar", es decir, realizar los principios de justicia, equidad, progresividad y capacidad económica. Por eso operan al interior del tributo y contribuyen a la exacta definición y cuantificación del supuesto de hecho, de la base gravable y del monto de la tarifa tributaria, por lo tanto, afectan a la riqueza o al sujeto gravado con base en consideraciones que obedecen fundamentalmente a su aptitud para contribuir a sufragar los gastos públicos. (Sentencia C-540, 2005, pp. 13-14).

De las minoraciones, Plazas (2019) ha señalado dos consideraciones. Una, estas no deben ser consideradas como gasto público indirecto por la vía de la renuncia a la recaudación. Dos, estas no son de recibo en el régimen del impuesto sobre la renta, sino en general en el de los tributos que integran el sistema y, entre ellos, en el del Impuesto sobre el Valor Agregado (IVA).

Volviendo con el tema de los beneficios tributarios, no menos importante es anotar que la gran incidencia que poseen los beneficios tributarios, tanto en los contribuyentes como en el presupuesto del gasto público nacional, es conveniente y necesario en la planeación tributaria del Estado tener en consideración que la disminución en el recaudo fiscal se debe encontrar ple- 
namente respaldada en el presupuesto de gastos del Estado, para evitar futuros déficits fiscales que ponen en riesgo la estabilidad de las finanzas públicas (Sentencia C-870, 2014).

Con base en lo anterior, se comparte la recomendación que ofrece el tributarista Sarmiento Pérez (2013) al señalar que "los beneficios tributarios deben contar con una correspondencia clara y precisa respecto de las medidas de los incentivos y los objetivos que se planea alcanzar, respaldados con una labor continua de seguimiento y evaluación” (p. 300).

Como se señaló en alguna oportunidad, el establecimiento de los beneficios tributarios no está exento de críticas en la doctrina, es tanto que algunos proponen su eliminación (Plazas, 2019). Se encontraron fuertes críticas doctrinarias frente a los beneficios tributarios, al afirmar que estos incentivos, así estén acordes a los principios de justicia, equidad y progresividad, generan consecuencias negativas como la disminución en el recaudo, así como también inequidad entre empresas e individuo. Por ejemplo, Macías Cardona, Agudelo Henao y López Ramírez (2007) señalan lo siguiente:

Son diversos los planteamientos disponibles sobre las estrategias para aumentar el recaudo [...] pero existen otras corrientes que hacen un énfasis especial en las exenciones, resaltando su influencia adversa. La disminución en el recaudo por cuenta de las exenciones en renta ha adquirido relevancia desde que se implementó un conjunto complejo e inestable de beneficios tributarios, introducidos en sucesivas reformas que autorizaron "ingresos que no constituyen renta ni ganancia ocasional", $[\ldots]$ "deducciones en el impuesto sobre la renta" [...] y "descuentos tributarios en el impuesto sobre la renta". (Macías, Agudelo \& López, 2007, p. 71).

Teniendo en cuenta lo abordado en este parte, es posible afirmar sin rodeos que es conveniente hablar de derecho económico cuando se hace referencia al derecho tributario, por la estrecha conexión que existe entre la institución intervención del Estado en la economía con el derecho tributario o con la política tributaria.

Es bueno señalar que hay autores que consideran que el régimen jurídico tributario es de derecho económico. Ramírez Cardona (1990), por ejemplo, señaló que el derecho tributario está ubicado dentro del derecho económico en general, que "tiene que ver con el grado de intervencionismo del Estado en la economía y el alcance de la función social de la propiedad privada" (p. 9). En el mismo sentido ha explicado Palacios Mejía (1999), citado por Franco (2013), al incluir en el derecho económico el derecho tributario, así como también el derecho presupuestal.

Barón Barrera (2016) también ha explicado que el derecho tributario es un derecho económico "pues confluyen en él derecho privado y derecho público" (p. 88), para este autor, se repite, el derecho económico es un derecho mixto con relación al derecho privado y al derecho público.

De otro lado, el jurista de derecho penal económico Prías Bernal (2004) también ha señalado que el derecho tributario forma parte del derecho económico, desde luego este jurista no explica las razones para ubicar al derecho tributario dentro del derecho económico. 


\subsubsection{La aplicabilidad de la política económica en el derecho tributario}

Se había mencionado en alguna oportunidad que una de las herramientas que le sirven al Estado para intervenir en la economía es la política económica, y forma parte del campo de estudio de la Constitución económica y del derecho económico. Como se evidenció, en el derecho tributario también se aplica la política económica, pues la política tributaria es dependiente de la política económica, y, por tal razón, forma parte del derecho económico y, por qué no, del Análisis Económico del Derecho (AED).

En el derecho tributario como campo específico de la teoría económica, la política económica se presenta como una disciplina positiva que tiene por objeto el estudio de los efectos económicos producidos por la función tributaria (Muñoz, 2010), de ahí surge la conexión entre la política económica con la política tributaria y, por tanto, es conveniente hablar de derecho económico y no de derecho administrativo, como lo han sostenido algunos juristas del derecho público, cuando se refiere al derecho tributario. Es necesario recordar que en el derecho administrativo se estudia la función administrativa (criterio material).

Es pertinente señalar que la política económica a partir del tributo puede manifestarse, entre otros, en estos momentos: a) el de la detracción de una parte de la riqueza privada para ser transferida al Estado y b) el de la erogación por parte de este para efectuar el gasto o la inversión pública (Bravo, 2009). De esta manera, se puede afirmar que el gasto público se constituye como el verdadero estímulo para la economía; de ahí la importancia que cobra en la obtención de recursos, a través de los tributos, para la ejecución de dicho gasto, generando a su vez estabilidad y desarrollo económico.

Por su parte, la Legislación española ha señalado la función del tributo como un verdadero instrumento de política económica que excede de su finalidad recaudatoria, pues así lo da a entender el numeral 1 artículo 2 de la Ley General Tributaria (conocida como LGT):

Los tributos son los ingresos públicos que consisten en prestaciones pecuniarias exigidas por una Administración pública como consecuencia de la realización del supuesto de hecho al que la ley vincula el deber de contribuir, con el fin primordial de obtener los ingresos necesarios para el sometimiento de los gastos públicos.

Los tributos, además de ser medio para obtener los recursos necesarios para el sometimiento de los gastos públicos, podrán servir como instrumentos de la política económica general y atender a la realización de los principios y fines contenidos en la Constitución. (Ley 58, 2003, numeral 1, artículo 2).

\subsection{3. ¿Por qué no la denominación "derecho económico público"?}

En la academia se han preguntado si es conveniente o no hablar de derecho económico público cuando se hace referencia al derecho tributario, definido como el derecho de la economía pública legislada, o como el derecho del orden público económico (Velilla, 2013), que coincide con la línea de investigación adoptada en este trabajo: el derecho de la intervención del Estado en la economía. 
Algunos afirmarán que esta denominación resulta coherente. En este trabajo se considera inconveniente esta denominación porque implícitamente se están aceptando otras clasificaciones, se constituiría en una lista interminable, entre otras: derecho económico privado, derecho económico constitucional, derecho económico internacional; presentándose así una "disputa de clasificaciones" (Carrió, 1990, p. 98).

Buena parte de las controversias consiste en problemas de clasificación, abordados como si se tratare de cuestiones de hecho [...] Las clasificaciones no son ni verdaderas, ni falsas, son serviciales o inútiles [...] las disputas clasificadoras de los juristas pueden ser interminables si en lugar de allegar argumentos valorativos, en favor de un modo de clasificar, los contendores se empeñan en mostrar que la clasificación propia - y no ajena - refleja la verdadera (naturaleza de las cosas), o es la única clasificación compatible con la (esencia) de los objetos clasificados. Mucho tiempo y mucha tinta se habrían ahorrado con solo recordar cosas tan simples. (Carrió, 1990, pp. 99-100).

De esta manera, en este trabajo se critica la denominación derecho económico público, pues el derecho económico es uno solo, así esté en el contexto o escenario del derecho público o del derecho privado. Resulta coherente utilizar la denominación derecho económico y con ello se evita confusiones.

\subsubsection{La aplicación del AED en el derecho tributario}

En el campo de estudio del derecho económico, una de las metodologías más utilizadas por juristas y economistas es el Análisis Económico del Derecho (AED) conocida también como Law and Economics (en español, derecho y economía). El cual consiste, como ya se indicó, en una metodología de evaluación de las instituciones jurídicas con criterios económicos.

Uno de los estudios que han desarrollado a partir del AED es la eficiencia. La eficiencia es también aplicable en el derecho tributario; pues, con acierto lo explica Barón (2016), la eficiencia en materia tributaria consiste en que "el recaudo tributario y los objetivos perseguidos por este deben hacerse al menor costo posible" (p. 89), pese a que en la práctica se ha identificado dificultad en la recaudación de tributos. Sobra anotar que la experiencia ha demostrado que los impuestos indirectos (IVA, por ejemplo) son de fácil cobro, en tanto que los directos (impuesto de renta, por ejemplo) son de difícil cobro.

Permite, entonces, concluir que es conveniente hablar de derecho económico y no de derecho administrativo cuando se hace referencia al derecho tributario, por la evidente conexión que existe de la institución de intervención del Estado en la economía con el derecho tributario o con la política tributaria.

\section{Conclusiones}

- El derecho económico es definido como el derecho de la intervención del Estado en la economía. En tanto que el derecho administrativo es el derecho de la Administración pública o de la función administrativa. 
- El régimen tributario (o el sistema tributario, para algunos), el cual forma parte del campo de estudio del derecho tributario, tiene su fundamento en la Constitución Política, sometido a unos principios constitucionales, entre otros, progresividad, eficiencia, equidad; por tal razón, el derecho tributario no puede ser concebido como un derecho autónomo.

- El tributo como objeto de estudio del derecho tributario (o de la política tributaria) tiene incidencia práctica en el intervencionismo del Estado en la economía, pues, el Estado utiliza la política tributaria - la cual forma parte de la política económica- a través del establecimiento y regulación de tributos para intervenir en la economía en casos de distorsiones en el mercado.

- Se concluye sin rodeos, y está demostrado, que es conveniente hablar de derecho económico y no de derecho administrativo, cuando se hace referencia al derecho tributario, por la estrecha conexión que existe entre la institución: intervención del Estado en la economía con el derecho tributario o con la política tributaria; debe recordarse que en el derecho administrativo se estudia lo relacionado con la función administrativa.

- En el campo de estudio del derecho tributario, por ser un derecho económico, es perfectamente aplicable el Análisis Económico del Derecho (AED), el cual permite estudiar las normas jurídicas tributarias con criterios económicos. Con la implementación del AED contribuye a aplicar de manera adecuada el principio de eficiencia tributaria.

\section{Referencias}

Amado Abril, J. H. (2017). Del Derecho Administrativo Global [notas de clase] Maestría en Derecho Administrativo. Pereira, Colombia: Universidad Libre.

Amador Cabra, L. E. (2014). Análisis Económico del Derecho. En Serie de Derecho Económico No. 3 (pp. 13-50). Bogotá, Colombia: Ediciones Universidad Externado de Colombia.

Ariño Ortiz, G. (2003). Principios de Derecho Público Económico (1. ${ }^{a}$ Ed.). Bogotá, Colombia: Ediciones Universidad Externado de Colombia.

Ariza Sánchez, C. E. (2000). Principios del derecho tributario. Ibagué: Ediciones Unibagué.

Atehortúa Ríos, C. A. (2017). Teoría económica en el régimen jurídico de los servicios públicos domiciliarios [notas de clase] Maestría en Derecho Administrativo. Pereira, Colombia: Universidad Libre

Avellaneda Bautista, C. A. (1997). La ciencia tributaria (1. ${ }^{a}$ Ed.). Bogotá, Colombia: Ediciones Multiletras Editores Ltda.

Ayala Caldas, J. E. (1994). Elementos del Derecho Administrativo colombiano (1. ${ }^{a}$ Ed.). Bogotá, Colombia: Ediciones Doctrina y Ley.

Ayala Caldas, J. E. (2009). Estructura de la rama ejecutiva en Colombia (1. ${ }^{a}$ Ed.). Bogotá, Colombia: Ediciones Doctrina y Ley Ltda.

Barón Barrera, G. A. (2016). Transformación del derecho administrativo en derecho económico (1. ${ }^{a}$ Ed.). Bogotá, Colombia: Ediciones de la U. 
Barros Carvalho, P. (2016). Teoría de la norma tributaria (2. ${ }^{a}$ Ed.). Bogotá, Colombia: Ediciones Editorial Temis.

Bravo Arteaga, J. R. (2009). Nociones fundamentales de derecho tributario (3. ${ }^{a}$ Ed.). Bogotá, Colombia: Ediciones Legis.

Bravo González, J. D. (2012). Procedimiento tributario territorial-principios estructurales de unidad nacional y autonomía de las entidades territoriales. En Estudios críticos de jurisprudencia tributaria Tomo II (pp. 329-337). Bogotá, Colombia: Ediciones Universidad Externado de Colombia.

Briceño de Valencia, M. T. (2012). El procedimiento contencioso administrativo tributario en la Ley 1437 de 2011. En Instituciones del derecho administrativo en el nuevo Código. Una mirada a la luz de la Ley 1437de 2011 (pp. 384-414). Bogotá, Colombia: Ediciones Consejo de Estado - Banco de la República.

Cadavid Arango, L. A. (2014). Fundamentos de derecho comercial, tributario y contable (4. ${ }^{a}$ Ed.). Bogotá, Colombia: Ediciones Mc Graw Will.

Carrió, G. R. (1990). Notas sobre derecho y lenguaje. Documento compartido en PDF en la Maestría en Derecho Administrativo. Pereira, Colombia. Universidad Libre.

Carrillo, F. \& Pinzón, J. (1985). Sector financiero y delincuencia económica (1. ${ }^{a}$ Ed.). Bogotá, Colombia: Ediciones Editorial TEMIS.

Cassagne, J. C. (1999). Derecho Administrativo Tomo I (7. ${ }^{a} E d$.). Buenos Aires, Argentina: Ediciones Lexis Nexis-beledo Perrot.

Charles Pool. J. \& M. LaRoe, R. (1991). Cómo comprender los conceptos básicos de la economía (1. ${ }^{a}$ Ed.). Bogotá, Colombia: Grupo Editorial Norma.

Colombia. Ley 1437 del 2011. Código de Procedimiento Administrativo y de lo Contencioso Administrativo. Recuperado de http://www.secretariasenado.gov.co/senado/basedoc/ley_1437_2011.html

Constitución Política de Colombia (1991). Colombia: Legis. Recuperada de http://www.secretariasenado. gov.co/senado/basedoc/constitucion_politica_1991.html

España. Ley 58 del 2003. Ley General Tributaria, LGT. Recuperada de https://www.boe.es/buscar/act. php?id=BOE-A-2003-23186

Farina, J. M. (1999) Contratos comerciales modernos (2. ${ }^{a}$ Ed.). Buenos Aires, Argentina: Ediciones Editorial Astrea de Alfredo y Ricardo Depalma.

Forero Hernández, C. F. (2016). La conveniencia de implementación del derecho tributario sancionador para reprimir a la conducta omisiva del agente retenedor o recaudador de consignar las respectivas sumas (Trabajo de grado para obtener el título de Abogado). Universidad de Ibagué, Ibagué, Colombia.

Forero Hernández, C. F. (2017a). Los riesgos y la ecuación económica en los contratos estatales. Temas y reflexiones, (6), 43-57. Recuperado de https://hdl.handle.net/20.500.12313/180

Forero Hernández, C.F. (2017b). El régimen jurídico del presupuesto público, ¿derecho administrativo o derecho económico? Revista Gestión y Finanzas, 1(2), 6-17. Recuperado de http://revistas.ut.edu.co/ index.php/gestionyfinanzas/article/view/1764/1363 
Forero Hernández, C. F. (2017c). El régimen jurídico de los actos administrativos del Banco de la República, ¿derecho administrativo o derecho económico? Dos mil tres mil, 19, 141-159. Recuperado de https://revistas.unibague.edu.co/dosmiltresmil/article/view/53

Franco Vargas, M. H. (2013). Derecho y economía. Una aproximación teórica (1. ${ }^{a}$ Ed.). Bogotá, Colombia: Ediciones Editorial Leyer.

Guerrero Orozco, O. (1997). Principios de la Administración Pública (1. ${ }^{a}$ Ed.). Bogotá, Colombia: Ediciones Escuela Superior de Administración Pública, ESAP.

Hernández Quintero, H. A. (1991). De los delitos económicos en la actividad financiera (1. ${ }^{a}$ Ed.). Bogotá, Colombia: Escuela Judicial "Rodrigo Lara Bonilla".

Hernández Quintero, H. A. (2015). De los delitos económicos en la actividad financiera (7. ${ }^{a}$ Ed.). Bogotá, Colombia: Ediciones Ibáñez.

Insignares Gómez, R. \& Sánchez Peña, M. C. (2010). El poder tributario: organización estructura en el estado colombiano. En Curso de derecho tributario, procedimiento y régimen sancionatorio (pp. 67112). Bogotá, Colombia: Ediciones Universidad Externado de Colombia.

Macías Cardona, H. A., Agudelo Henao, L. F. \& López Ramírez, M. R. (2007). Los métodos para medir la evasión de impuestos. Semestre Económico, (20), 67-85. Recuperado de https://revistas.udem.edu. co/index.php/economico/article/view/681

Miranda Talero, A. (1999). El derecho de las finanzas públicas. Actualizado (2. ${ }^{a}$ Ed.). Bogotá, Colombia: Editorial Legis.

Molina Betancur, C. M. (2007). La contratación estatal: Entre derecho público y privado. En Los Contratos en el Derecho Privado (1. ${ }^{a}$ Ed.) (pp. 721-750). Bogotá, Colombia: Ediciones Universidad del Rosario Editorial Legis.

Montaña Plata, E. A. (2010). Fundamentos de derecho administrativo (1. ${ }^{a}$ Ed.). Bogotá, Colombia: Ediciones Universidad Externado de Colombia.

Muñoz Martínez, G. (2010). Derecho tributario: concepto y fundamento de su autonomía científica. En Curso de derecho tributario, procedimiento y régimen sancionatorio (pp. 29-66). Bogotá, Colombia: Ediciones Universidad Externado de Colombia.

Olano García, H. A. (2007). Preguntas y respuestas de Derecho Administrativo (3. ${ }^{a}$ ed.). Bogotá, Colombia: Ediciones Doctrina y Ley Ltda.

Ortega Cárdenas, A. (2014). Hacienda Pública. Las finanzas del Estado (5. ${ }^{a}$ Ed.). Bogotá, Colombia: Ediciones Ecoe Ediciones.

Palacios Mejía, H. (1975). La economía en el derecho constitucional colombiano (1. ${ }^{a}$ Ed.). Bogotá, Colombia: Ediciones Biblioteca ANIF de Economía.

Parra Jiménez, O. D. \& Patiño Jacinto, R. A. (2010). Evasión de impuestos nacionales en Colombia: años 2001 2009. Revista Facultad de Ciencias Económicas, 18, (2), 177-198. https://doi.org/10.18359/ rfce. 2279 
Piffano, H. L. (2012) Análisis Económico del Derecho Tributario (1. ${ }^{a}$ Ed.). La Plata, Argentina: Ediciones Universidad Nacional de La Plata.

Pinzón Camargo, M. A. (2010). Del Derecho y la Economía al Derecho Económico. Working Paper nro. 1. Recuperado de https://works.bepress.com/mario_pinzon/14/

Piza Rodríguez, J. R. (2013). Evolución del impuesto sobre la renta en el sistema tributario colombiano. En El impuesto sobre la renta y complementarios. Consideraciones teóricas y prácticas (3. ${ }^{a} \mathrm{Ed}$.) ( $p$ p. 23-67). Bogotá, Colombia: Ediciones Universidad Externado de Colombia.

Plazas Vega, M. A. (2008). Relación entre el derecho de la hacienda pública y el derecho tributario. En La autonomía del derecho de la hacienda pública y el derecho tributario. (pp. 79-115). Bogotá, Colombia: Ediciones Universidad del Rosario.

Plazas Vega, M. A. (2019). La ley de financiamiento desde una visión de hacienda pública y derecho tributario (1. ${ }^{a}$ Ed.). Bogotá, Colombia: Ediciones Editorial Temis.

Prías Bernal, J. C. (2004). El ilícito tributario ante el derecho penal (1. ${ }^{a}$ Ed.). Bogotá, Colombia: Ediciones Doctrina y Ley Ltda.

Quiroga Natale, E. A. (2016). De la Hacienda Pública [notas de clase] Maestría en Derecho Administrativo. Pereira, Colombia: Universidad Libre

Ramírez Cardona, A. (1990). Derecho tributario. Del derecho sustancial tributario (4. ${ }^{a}$ Ed.). Bogotá, Colombia: Ediciones Temis.

Ramírez Grisales, R. S. (2013). La autorregulación en el Derecho Administrativo (1. ${ }^{a}$ Ed.). Medellín, Colombia: Ediciones Librería Jurídica Sánchez Ltda - Centro de Estudios de Derecho Administrativo, ceda.

Rivero, J. (2006). Derecho Administrativo (9. ${ }^{a}$ Ed.). Traducido por la Facultad de Ciencias Jurídicas y Políticas de la Universidad Central de Venezuela. París, Francia: Ediciones Dalloz París.

Rodríguez Rodríguez, L. (2000). Derecho Administrativo. General y colombiano (12. ${ }^{a}$ Ed.). Bogotá, Colombia: Ediciones Editorial Temis.

Romero Alvarado, L. M. (2013). Derecho y economía. Derecho y realidad, 11 (21), 271-284. https://doi. org/10.19053/16923936.v2.n21.2013.4842

Sánchez Torres, C. A. (1995). Teoría general del acto administrativo (1. ${ }^{a}$ Ed.). Medellín: Ediciones Biblioteca Jurídica Diké.

Sánchez Torres, C. A. (2007). Constitución Económica (1. ${ }^{a}$ Ed.). Bogotá, Colombia: Ediciones Escuela Judicial “Rodrigo Lara Bonilla”- Universidad Sergio Arboleda (Bogotá).

Santamaría Pastor, J. A. (2011). Los principios jurídicos del derecho administrativo (1 ${ }^{a}$ Ed.). Madrid, España: Ediciones Wolters Klower.

Santofimio Gamboa, J. O. (1996). Tratado de derecho administrativo. Tomo I. Bogotá: Ediciones Universidad Externado de Colombia

Sarmiento Pérez, P. E. (2013). Beneficios tributarios del impuesto sobre la renta en Colombia. En El impuesto sobre la renta y complementarios. Consideraciones teóricas y prácticas (3. ${ }^{a} \mathrm{Ed}$.) (pp. 273-303). Bogotá, Colombia: Ediciones Universidad Externado de Colombia. 
Sentencia C-015 (1993). Corte Constitucional de Colombia. Magistrado ponente: Eduardo Cifuentes Muñoz.

Sentencia C-1108 (2001). Corte Constitucional de Colombia. Magistrados ponentes: Rodrigo Escobar Gil y Marco Gerardo Monroy Cabra.

Sentencia C-150 (2003). Corte Constitucional de Colombia. Magistrado ponente: Manuel José Cepeda Espinosa.

Sentencia C-989 (2004). Corte Constitucional de Colombia. Magistrada ponente: Clara Inés Vargas Hernández.

Sentencia C-540 (2005). Corte Constitucional de Colombia. Magistrado ponente: Humberto Antonio Sierra Porto.

Sentencia C-870 (2014). Corte Constitucional de Colombia. Magistrado ponente: Luis Guillermo Guerrero Pérez.

Sentencia C-891 (2012). Corte Constitucional de Colombia. Magistrado ponente: Jorge Ignacio Pretelt Chaljub.

Tafur Galvis, Á. (1996). Estudios de derecho público. Acto administrativo y el concepto de derecho administrativo (1. ${ }^{a} \mathrm{Ed}$.). Bogotá, Colombia: Ediciones Jurídicas Gustavo Ibáñez.

Velilla Moreno, M.A. (20013). Introducción al derecho económico y de los negocios ( $1^{a}$ Ed.). Bogotá, Colombia: Ediciones: Editorial Planeta Colombiana S.A.

Vidal Perdomo, J. (2004). Derecho Administrativo (12. ${ }^{a}$ Ed.). Bogotá, Colombia: Ediciones Editorial Legis Universidad del Rosario.

Younes Moreno, D. (2016). Curso de Derecho Administrativo (10. ${ }^{a}$ Ed.). Bogotá, Colombia: Ediciones Editorial Temis S.A.

\section{Bibliografía recomendada}

Barón Barrera, G. A. (2016). Transformación del derecho administrativo en derecho económico (1. ${ }^{a}$ Ed.). Bogotá, Colombia: Ediciones de la U.

Ramírez Cardona, A. (1990). Derecho tributario. Del derecho sustancial tributario (4. ${ }^{a}$ Ed.). Bogotá, Colombia: Ediciones Temis. 